\title{
KESEJAHTERAAN DALAM PERSPEKTIF ISLAM PADA KARYAWAN BANK SYARIAH')
}

\author{
Ziauddin Sardar \\ Program Studi S1 Ekonomi Islam-Fakultas Ekonomi dan Bisnis-Universitas Airlangga \\ Email: ziauddinsardar@gmail.com \\ Muhammad Nafik H.R \\ Departemen Ekonomi Syariah-Fakultas Ekonomi dan Bisnis-Universitas Airlangga \\ Email: manhard999@yahoo.com
}

\begin{abstract}
:
Muslims required to work through legal means, but as human beings sometimes lust to dominate oneself so a man would prefer to work in a place that is run in activities contrary to the rules of Islam simply because the payment is obtained at the site is greater. The purpose of this research was to determine how the financial and non-financial welfare of employees and the Islamic banks to determine the reasons employees relocate to Islamic banks. For the informants who have the motivation to move because of a reason to avoid usury laws, could be said to be better in terms of non-financial welfare. For the informant who aim to move into Islamic banks due to other reasons, in terms of the welfare of both financial and nonfinancial could be said to be prosperous just not better than the employees who move for some reason wants to avoid usury.
\end{abstract}

\section{Keywords: Employees, Welfare, Financial, Non-Financial}

\section{PENDAHULUAN}

Dalam ajaran agama Islam bekerja merupakan ibadah, dimana hakikat hokum ibadah adalah wajib. Sehingga dapat ditarik kesimpulan bahwa bekerja adalah kewajiban bagi umat Muslim. Bagi seorang Muslim, makna bekerja berarti niat yang kuat untuk mewujudkan hasil kerja yang optimal, bukan hanya memberikan nilai rata-rata.

Agama Islam memiliki pandangan bahwasanya seseorang yang bersusahpayah untuk mencari rezeki yang halal dan hasilnya digunakan sepenuhnya di jalan Allah disamakan derajatnya dengan para mujahid yang berperang di jalan Allah. Seorang Muslim ketika kelelahan dalam mencari rezeki dinilai oleh Allah sebagai pahala. Bahkan bisa jadi penebus dosa. Orang yang pulang ke 1) Jurnal ini merupakan bagian dari skripsi Ziauddin, NIM : 041114007, yang diuji pada tanggal 9 Februari 2016

rumah dalam keadaan kepayahan karena seharian bekerja akan diampuni dosanya oleh Allah SWT.

Islam memandang bahwa bekerja bukan sekedar memnuhi kebutuhan hidup, tapi juga untuk memelihara harga diri dan martabat kemanusiaan yang seharusnya dijunjung tinggi. Karenanya, bekerja dalam Islam menempati posisi yang teramat mulia. Islam sangat menghargai orang yang bekerja dengan tangannya sendiri. Bekerja memiliki kaitannya dengan martabat manusia. Seseorang yang telah bekerja dan bersungguh-sungguh dalam pekerjaannya akan bertambah martabat dan kemuliannya. Sebaliknya, orang yang tidak bekerja atau menganggur, selain kehilangan martabat dan harga diri di 
hadapan dirinya sendiri, juga di hadapan orang lain. Jatuhnya harkat dan harga diri akan menjerumuskan manusia pada perbuatan hina. Tindakan mengemis merupakan kehinaan, baik dari sisi manusia maupun dari sisi Allah SWT.

Seseorang memiliki dorongan untuk bekerja adalah agar mendapatkan penghasilan untuk memenuhi kebutuhan hidup. Menurut teori hirarki kebutuhan Maslow motivasi untuk mendapatkan rasa aman merupakan motivasi yang dominan pada setiap manusia, termasuk rasa aman dalam hal pendapatan atau kebutuhan untuk mendapatkan keamanann selama hidupnya.

Semakin pesatnya perkembangan Ekonomi Islam di Indonesia berbanding lurus dengan semakin maraknya lembaga pendidikan yang mengajarkan tentang sistem Ekonomi Islam maupun Lembaga Kevangan yang berbasis Syariah. Dalam bentuk praktiknya, ekonomi Islam telah berkembang dalam bentuk kelembagaan seperti perbankan, BPRS, Asuransi Syariah, Pegadaian Syariah, Pasar Modal Syariah, dengan instrumen obligasi dan Reksadan Syariah, Dana Pensiun Syariah, Lembaga Keuangan Mikro Syariah, maupun lembaga keuangan publik Islam seperti lembaga pengelola zakat dan lembaga pengelolaan wakaf.

Berdasarkan data dari OJK, secara keseluruhan sampai dengan bulan Januari 2015 jumlah pekerja pebankan Syariah di Indonesia mencapai 58.587 karyawan dimana yang paling besar adalah karyawan di Bank Umum Syariah yang mencapai 49.089 karyawan. (Statistik Perbankan Syariah 2015). Data diatas menunjukkan bahwa dari tahun ke tahun jumlah karyawan perbankan syariah terus meningkat. Karyawan merupakan suatu aset yang berharga bagi sebuah perusahaan termasuk Perbankan. Tanpa adanya karyawan sebagai sumber daya manusia yang baik maka tujuan perusahaan tidak dapat tercapai dengan baik.

Kesejahteraan sendiri memiliki banyak arti dimana masing - masing orang pasti mempunyai perspektif sendiri mengenai apa yang disebut dengan kesejahteraan. Akan tetapi pada umumnya kesejahteraan sendiri secara umum bisa dibagi dalam dua bentuk, yaitu kesejahteraan secara materi dan kesejahteraan secara non materi. Kesejahteraan materi meliputi berapa jumlah harta yang kita miliki, berapa pendapatan yang kita dapatkan, dan apa saja yang sifatnya bisa dimaterialkan. Sementara kesejahteraan non materi adalah kesejahteraan yang kita miliki dimana kesejahteraan tersebut tidak berbentuk barang atau sejenisnya, misalnya adalah kesehatan yang kita rasakan, memiliki anak yang sholeh dan sholehah, dan lain sebagainya. Kesejahteraan menurut Islam meliputi kesejahteraan dari sisi materi dan juga non materi. Islam mengajarkan bahwasanya harta bukanlah satu satunya indicator kesejahteraan karena 
pada dasarnya harta hanyalah alat yang digunakan untuk tujuan beribadah kepada Allah SWT.

Penelitian ini dibuat untuk mengetahui bagaimana kesejhateraan financial dan non finasial pegawai bank Syariah, sehingga dapat diambil manfaat yang mungkin berguna untuk orang lain.

\section{LANDASAN TEORI}

Allah SWT telah menyebarkan rezeki untuk manusia di bumi dan langit. Untuk memperoleh rezeki tersebut, manusia tentu harus berusaha. Salah satu bentuk usaha dalam memperoleh rezeki adalah dengan bekerja. Dengan bekerja maka manusia akan mendapatkan imbalan berupa gaji atau pendapatan. Pendapatan tersebut digunakan untuk memenuhi segala kebutuhan hidupnya. Bekerja bisa diartikan dalam dua bentuk, yaitu bekerja sebagai pengusaha atau bekerja sebagai pegawai/karyawan dalam sebuah perusahaan. Manusia ketika bekerja untuk mendapatkan rezeki, harus melakukannya dengan kemampuan terbaik yang dia miliki, dengan ikhlas, dan juga dengan jujur sehingga rezeki yang dia dapatkan menjadi berkah dan keberkahan tersebut pada akhirnya akan berujung kepada kehidupan yang aman dan tentram.

$$
\text { Manusia dalam menjalani }
$$

kehidupannya tentu tidak boleh hanya terfokus kepada pencarian rezeki dan pendapatan saja sampai melupakan ibadahnya dan menjauh dari Allah SWT, karena sesungguhnya yang memberikan manusia rezeki dan pendapatan adalah Allah SWT. Allah SWT sama sekali tidak membutuhkan rezeki apapun dari manusia, akan tetapi Allah SWT lah yang memberikan rezeki kepada manusia. Hal ini dijelaskan Allah dalam surat Adz-Zariyat ayat $56-58$ :

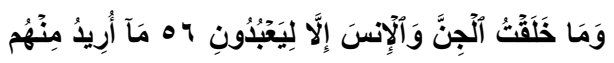

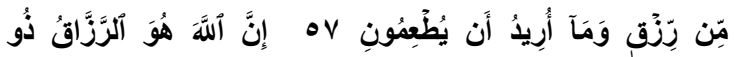

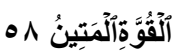

Artinya : "(56). dan aku tidak menciptakan jin dan manusia melainkan supaya mereka mengabdi kepada-Ku. (57) aku tidak menghendaki rezki sedikitpun dari mereka dan aku tidak menghendaki supaya mereka memberi-Ku makan.(58) Sesungguhnya Allah Dialah Maha pemberi rezki yang mempunyai kekuatan lagi sangat kokoh.

Menurut Sutrisno (2009:124-129),
"faktor-faktor yang menyebabkan
seseorang bekerja dapat
dikategorikan menjadi dua faktor,
yaitu faktor intrinsik dan faktor
ekstrinsik. Faktor intinsik faktor yang
berasal dari dalam diri, sedangkan
faktor ekstrinsik adalah faktor yang
berasal dari luar diri seseorang".

Faktor yang berasal dari dalam diri (intrinsik) yaitu :

1. Keinginan untuk dapat hidup

2. Keinginan untuk dapat memiliki

3. Keinginan untuk memperoleh penghargaan

4. Keinginan untuk memperoleh pengakuan

5. Keinginan untuk berkuasa Faktor yang berasal dari luar (ekstrinsik) yaitu :

1. Kondisi lingkungan kerja

2. Kompensasi yang memadai 
3. Adanya jaminan pekerjaan

4. Status dan tanggung jawab Bekerja diartikan melakukan suatu kegiatan untuk menghasilkan pendapatan demi terpenuhinya kebutuhan hidup.Banyak sekali faktor yang mendorong manusia untuk bekerja, salah satunya adalah untuk memenuhi kebutuhan. Sedangkan dalam Islam, bekerja dikategorikan sebagai ibadah sehingga wajib dilakukan oleh seluruh umat Muslim. Bekerja merupakan perbuatan yang sangat mulia dalam ajaran Islam. Rasulullah Shallallahu 'Alaihi wa Sallam memberikan pelajaran menarik tentang pentingnya bekerja. Dalam Islam bekerja bukan sekedar memenuhi kebutuhan perut, tapi juga untuk memelihara harga diri dan martabat kemanusiaan yang seharusnya dijunjung tinggi. Karenanya, bekerja dalam Islam menempati posisi yang teramat mulia. Islam sangat menghargai orang yang bekerja dengan tangannya sendiri. Hal ini sebagaimana firman Allah SWT dalam surat At-Taubah ayat 105 yang artinya:

"Dan Katakanlah: "Bekerjalah kamu, Maka Allah dan Rasul-Nya serta orang-orang mukmin akan melihat pekerjaanmu itu, dan kamu akan dikembalikan kepada (Allah) yang mengetahui akan yang ghaib dan yang nyata, lalu diberitakan-Nya kepada kamu apa yang telah kamu kerjakan".

Menurut Qardhawi (2007:152), dibolehkannya bekerja sebagai pegawai adalah dengan syarat apabila tugas itu tidak menimbulkan madharat bagi kaum Muslimin. Oleh karena itu, tidak halal seorang Muslim menjadi pegawai atau menjadi prajurit yang memerangi kaum Muslimin. Tidak halal pula dia bekerja pada suatu perusahaan atau pabrik yang memproduksi senjata untuk memerangi kaum Muslimin. Atau ia tidak boleh bekerja sebagai pegawai suatu lembaga yang memusuhi Islam dan memerangi kaum Muslimin.

Qardhawi

(2007;152) juga menjelaskan demikian pula halnya orang yang bekerja sebagai pegawai yang tugasnya membantu tindakan kezhaliman atau sesuatu yang haram, maka hukumnya adalah haram. Seperti orang yang bekerja dalam suatu pekerjaan yang berkaitan dengan praktik riba atau di tempat pembuatan khamr, di tempat dansa, atau di tempat-tempat permainan yang bertentangan dengan normanorma syari'at dan sebagainya.

$$
\text { Menurut P3El }
$$

(2008:4), kesejahteraan menurut Islam mencakup dua pengertian, yaitu :

1. Kesejahteraan holistik dan seimbang, yaitu kecukupan materi yang didukung oleh terpenuhinya kebutuhan spiritual serta mencakup individu dan sosial. Sosok manusia terdiri atas unsur fisik dan jiwa, karenanya kebahagiaan haruslah menyeluruh dan seimbang diantara keduanya. Demikian pula manusia memiliki dimensi individual sekaligus sosial. Manusia akan merasa bahagia jika terdapat keseimbangan diantara 


\author{
dirinya dengan lingkungan \\ sosialnya.
}

2. Kesejahteraan di dunia dan akhirat (falah), sebab manusia tidak hanya hidup di alam dunia saja, tetapi juga di alam setelah kematian/kemusnahan dunia (akhirat). Kecukupan materi di dunia ditunjukkan dalam rangka untuk memperoleh kecukupan di akhirat. Jika kondisi ideal ini tidak tercapai maka kesejahteraan di akhirat tentu lebih diutamakan, sebab ini merupakan sesuatu yang abadi dan lebih bernilai (valuable) dibanding kehidupan dunia.

Kesejahteraan dalam Ekonomi Islam adalah kesejahteraan secara menyeluruh, yaitu kesejahteraan secara material maupun secara spiritual. Konsep kesejahteraan dalam ekonomi Islam tidak hanya diukur berdasarkan nilai ekonomi saja, tetapi juga mencakup nilai moral, spiritual, dan juga nilai sosial. Sehingga kesejahteraan berdasarkan Islam mempunyai konsep yang lebih mendalam.

Kesejahteraan hidup seseorang pada realitasnya memiliki banyak indikator yang dapat diukur. Pengukuran tingkat kesejahteraan seseorang juga sering mengalami perubahan dari waktu ke waktu. Pada tahun 1950-an kesejahteraan diukur dari aspek fisik seperti berat badan, tinggi, dan gizi, harapan hidup serta income. Pada tahun 1980-an terjadi perubahan dimana kesejahteraan diukur dari income, tenaga kerja dan hak-hak sipil. Pada tahun 1990-an terjadi perubahan lagi, Mahbub Ul-Haq merumuskan ukuran kesejahteraan dengan Human Development Index (HDI). Dengan HDI, kesejahteraan tidak lagi ditekankan pada aspek ekonomi saja, tetapi juga pada aspek kualitas sosial individu. HDI merupakan gabungan dari tiga komponen, yaitu indeks harapan hidup, indeks pendidikan, dan indeks pendapatan per kapita.

Hakim (2013) mengatakan ekonomi konvensional membuat indikator kesejahteraan berdasarkan beberapa sudut pandang yang berbeda, diantaranya adalah :

1. Adam Smith, dalam buku "The Wealth of Nation" menyatakan bahwa kesejahteraan rakyat akan tercapai bila dipenuhi empat prinsip ekonomi dasar, yaitu : (a) Prinsip keseimbangan produksi dan konsumsi; (b) Prinsip manajemen tenaga kerja; (c) Prinsip manajemen modal; (d) Prinsip kedaulatan ada di tangan rakyat.

2. Menurut Miles (1985), terdapat empat indikator yang digunkan untuk mengetahui kesejahteraan suatu keluarga, yaitu :
a. Rasa aman (security)
b. Kebebasan (freedom)
c. Kesejahteraan (welfare)
d. Jati diri (identity)

Menurut beberapa ahli dalam buku P3EI (2008: 1-13), "indikator kesejahteraan Islami adalah 
terpenuhinya kebutuhan fisik dari rizqi yang halal, hidup sehat secara jasmani dan rohani, keberkahan rezeqi yang diterima, keluarga yang sakinah mawaddah wa rahmah, rasa cinta kasih sesama, ridha dan qana'ah dengan apa yang diberikan Allah kepadanya serta merasa bahagia".

Dengan demikian, kesejahteraan dalam Islam tidak hanya diukur dari terpenuhinya kebutuhan materi saja, tetapi juga terpenuhinya kebutuhan spiritual.

a. Ad-dien : Memelihara agama

Ryandono (2010:30) mengatakan bahwa: memelihara agama dapat diukur dari implementasi rukun Islam (syahadat, shalat, puasa, zakat, dan haji). Selain itu juga bisa dilihat pula dari tercapainya amalan rukun iman.

b. An-nafs: Memelihara Jiwa

Ryandono (2010:30) berpendapat bahwa perwujudan pemeliharaan jiwa yaitu dengan dipenuhinya kebutuhan sandang, pangan, tempat tinggal, kesehatan, serta fasilitas umum lainnya.

c. Al-aql : Memelihara Akal

Menurut Al-Syatibhi dalam Bakri (1997) memelihara akal dapat dibedakan menjadi tiga peringkat. Dalam peringkat dharuriyah misalnya adalah diharamkannya meminum minuman keras. Dalam peringkat hajjiyah seperti dianjurkannya menuntut ilmu pengetahuan. Sedangkan dalam perigkat tahsiniyyah yaitu misalnya menghindarkan diri dari mendengarkan sesuatu yang tidak bermanfaat.

d. An-nasl : Memelihara Keturunan.

Kita sebagai manusia tidak perlu khawatir apabila masih belum mampu dalam hal ekonomi untuk menikah karena Allah SWT akan memberikan rezeki serta karunia-Nya.

e. Al-maal : Memelihara Harta.

Menurut Ryandono (2010:30), "cara menjaga harta adalah meliputi mencari pendapatan yang layak dan adil, memiliki kesempatan berusaha, rejeki yang halal dan thoyib, serta persaingan yang adil".

\section{METODE PENELITIAN}

\section{Pendekatan Penelitian}

Berdasarkan rumusan masalah yang telah ditetapkan sebelumnya, maka peneliti menetapkan metode penlitian yang digunakan untuk penelitian ini adalah kualitatif deskriptif. Hal ini dikarenakan berdasarkan rumusan masalah yang muncul menuntut peneliti untuk melakukan aktivitas eksplorasi untuk menjelaskan masalah-masalah yang menjadi fokus masalah dalam penelitian ini. Pengumpulan data dan informasi akan dilakukan melalui teknik wawancara dan observasi terhadap sumber-sumber data yang diperlukan

\section{Ruang Lingkup Penelitian}

. Ruang lingkup penelitian ini terbatas hanya pada alasan mengapa pegawai bank pindah dari bank konvensional ke bank syariah dan bagaimana kesejahteraan finansial dan non finansial pegawai bank Syariah.

\section{Jenis dan Sumber Data}

Data dalam penelitian kualitatif dibagi menjadi dua yaitu data primer dan data sekunder. Data primer adalah data yang berasal dari wawancara dan observasi langsung di lapangan, sehingga bentuk 
datanya lebih berwujud kata-kata dan tindakan dari objek penelitian. Sedangkan data sekunder adalah data yang sudah ada yang berkaitan dengan penelitian seperti dokumen.

\section{Unit Analisis}

Unit analisis digunakan untuk menyeleksi siapa saja yang akan dijadikan sebagai informan dari penelitian yang akan dilakukan. Individu yang akan peneliti jadikan sebagai informan dalam penelitian ini adalah pegawai bank syariah yang telah bekerja minimal selama lima tahun dan sebelumnya sudah pernah bekerja di bank konvensional minimal limatahun juga.

\section{Teknik Pengumpulan Data}

Langkah-langkah

yang

dilakukandalamprosedurpengumpulan

data adalah:

a. Persiapan awal.

Pada tahap ini, peneliti telah menghubungi informan yang bekerja sebagai pegawai bank di bank syariah tetapi sebelumnya sudah pernah bekerja di bank konvensional.

b. Saat di lokasi penelitian.

Peneliti menjelaskan maksud dan tujuan penelitian kepada informan bahwa peneliti akan melakukan penelitian tentang bagaimana kesejahteraan finansial dan non finansial pegawai bank Syariah, peneliti juga menanyakan tentang bagaimana kehidupan sehariharinya, pekerjaan, keluarga, apa saja kebutuhannya, dan lain-lain. Peneliti juga melakukan wawancara secara mendalam dan terbuka kepada pegawai bank tersebut. Kegiatan ini dilakukan sampai peneliti mendapatkan jawaban dari rumusan masalah yang telah dibuat sebelumnya.

\section{Pengumpulan data.}

Peneliti mendapatkan data dari hasil wawancara dengan pegawai bank yang menjadi obyek penelitian. Wawancara dilakukan secara terbuka dengan pertanyaan yang terus berkembang tetapi tetap terfokus dan mengarah pada topik penelitian. Hasil wawancara akan didokumentasikan sendiri oleh peneliti.

\section{Teknik Keabsahan Data}

Dalam peneltian ini menggunakan dua teknik keabsahan data, yaitu teknik ketekunan/keajegan pengamatan dan teknik triangulasi data. Ketekunan pengamatan yaitu menemukan ciri-ciri dan unsur-unsur dalam situasi yang sangat relevan dengan persoalan atau isu yang sedang dicari dan kemudian memusatkan diri pada hal-hal tersebut secara rinci

Triangulasi data adalah teknik pemeriksaan keabsahan data yang memanfaatkan sesuatu yang lain, diluar data itu untuk melakukan pengecekan atau sebagai pembanding terhadap data tersebut.

\section{Teknik Analisis Data}

Teknik analisis yang digunakan dalam penelitian ini adalah pendekatan analisis kualitatif fenomenologi. Inti dari riset fenomenologi adalah gagasan yang berhubungan dengan pemahaman realitas kehidupan dari masing-masing 
individu yang berbeda melalui perspektif bersama, sehingga tugas peneliti untuk mengakses pemikiran akal sehat orangorang dengan tujuan menafsirkan motifmotif, tindakan dan dunia sosial dari sudut pandang individu. Oleh karena itu, fenomenologi berupaya untuk memahami arti peristiwa dan kaitankaitannya terhadap orang-orang yang berada dalam situasi tertentu

\section{HASIL DAN PEMBAHASAN}

Dalam hal kesejahteraan finansial, semua informan yang telah diwawancarai oleh peneliti merasakan hal yang sama, yaitu saat mereka pindah ke bank Syariah dari bank konvensional, pendapatan atau gaji yang mereka dapatkan justru menurun dari gaji yang mereka dapatkan ketika bekerja di bank konvensional. Namun meskipu ngaji yang mereka dapatkan berkurang, mereka sama sekali tidak merasa kekurangan, mereka malah bersyukur dengan gaji yang mereka dapatkan. Bahkan ada salah satu informan yang mengatakan bahwa meskipun gajinya turun, tetapi beliau merasa bahwa gajinya itu cukup untuk memenuhi semua kebutuhannya. Padahal ketika beliau kerja di bank konvensional dan mendapatkan gaji yang lebih tinggi, beliau selalu merasa bahwa gajinya yang tinggi itu masih terasa kurang untuk memenuhi kebutuhannya. Beliau pun menganggap bahwa bekerja di bank Syariah meskipun gajinya lebih sedikit, tetapi hasilnya lebih barokah apabila dibandingkan dengan bekerja di bank konvensional dengan gaji yang lebih tinggi.

Dari segi kesejahteraan non finansial, semua informan bisa dikatakan sudah sejahtera. Dalam hal memelihara ibadah, semua informan sudah melaksanakan ibadah shalat wajib secara berjamaah karena mereka paham bahwa bagi seorang laki - laki hukumnya adalah wajib untuk melaksanakan shalat secara berjamaah. Selain melaksanakan shalat wajib, mereka juga rajin melaksanakan shalat sunnah, mulai dari shalat sunnah ba'diyah qobliyah, shalat dhuha, dan shalat tahajud meskipun masih belum bisa rutin untuk shalat tahajudnya. Untuk ibadah puasa selain puasa wajib di bulan Ramadhan, para informan juga rutin melaksanakan puasa Sunnah senin kamis, bahkan ada satu informan yang rutin melaksanakan puasa Daud, dan satu informan lagi yang sudah berniat untuk melaksanakan puasa Daud juga. Hal ini rutin mereka jalankan karena mereka sudah merasakan sendiri nikmat dan manfaat yang didapatkan apabila melaksanakan puasa dan juga sebagai sarana untuk beribadah kepada Allah SWT. Semua informan yang peneliti wawancarai juga rutin membayar zakat, ada yang membayarnya melalui lembaga zakat, ada juga yang menyalurkannya langsung ke masjid masjid di lingkungan rumah masing masing informan. Selain membayar zakat mereka juga rutin bersedekah ataupun 
Sardar, et al/Jurnal Ekonomi Syariah Teori dan Terapan Vol. 3 No. 5 Mei 2016: 391-401; KESEJAHTERAAN DALAM PERSPEKTIF ISLAM PADA KARYAWAN BANK SYARIAH

berinfaq sebagai sarana untuk berbagi dengan orang yang lebih membutuhkan.

\section{SIMPULAN}

Dilihat dari kesejahteraan baik itu kesejahteraan financial maupun non financial, tentu ada perbedaan yang cukup mendasar diantara pegawai bank syariah dengan pegawai bank konvensional. Dari sisi kesejahteraan financial, pegawai yang bekerja di bank Syariah rata - rata mendapatkan pendapatan atau gaji yang lebih kecil apabila dibandingkan dengan gaji pegawai bank konvensional. Akan tetapi meskipun lebih kecil, pegawai bank syariah tetap bersyukur dengan apa yang mereka dapatkan.

Sedangkan apabila dibandingkan antara pegawai bank syariah sebelum bekerja di bank syariah dengan setelah bekerja di bank syariah dari sisi kesejahteraan non financial maka bisa dipastikan bahwa pegawai yang telah bekerja di bank syariah lebih sejahtera dikarenakan pegawai yang telah bekerja di bank Syariah mengalami peningkatan dari sisi ibadahnya, baik itu berupa ibadah shalat wajib, shalat sunnah, puasa wajib, dan juga puasa sunnah. Salah satu hal yang menyebabkan tingkat ibadah pegawai bank Syariah meningkat adalah dikarenakan ketika bekerja di bank Syariah maka mereka secara langsung atau tidak langsung akan belajar agama Islam lebih dalam.

\section{DAFTAR PUSTAKA}

Abdul, Hakim. 2013. Pengaruh Dana Bantuan Langsung Masyarakat Terhadap Penyerapan Tenaga Kerja dan Perkembangan Usaha Tani Padi Serta Kesejahteraan Kelvarga Petani Kabupaten Kota di Provinsi Nusa Tenggara Barat Dalam Perspektif Islam. Disertasi tidak diterbitkan. Pascasarjana Universitas Airlangga.

Ahmad, Mustaq. 2011. Etika bisnis dalam Islam diterjemahkan dari business ethics in Islam. Pustaka Al-Kautsar

Al-Raysuni, Ahmad. 2006. Imam Al-Shatibi's Theory of the Higher Objectives and Intens of Islamic Law. Kuala Lumpur: The International Institute of Islamic Thought.

Aryogi, Ista. 2013. Kesejahteraan subjektif individu dalam rumah tangga di Indonesia. Skripsi tidak diterbitkan. Surabaya, Fakultas Ekonomi dan Bisnis Universitas Airlangga.

Bakri, Asafri Jaya. 1997. Konsep Maqashid Syariah menurut al-Syatibi. Jakarta: Logos wacana.

Daymon, Cristine dan Immy Holloway. 2008. Riset kualitatif dalam public relations dan marketing communications. Diterjemahkan oleh cahya wiratama. Yogyakarta: penerbit bintang.

Departemen Agama RI. 2009. Syamil AlQur'an (Al-Qur'an TerjemahanPerkata). Bandung: CV Haikal Centre Haughton, Jonathan dan Shahidur Khandker. 2006. Handbook on Poverty 
and Inequality. Washington : World Bank.

Hasan, muhammad Tholhah. 2003. Islam dan masalah sumber daya manusia. Jakarta : lantabora press.

Heryawan, Ahmad. 2009. "Kesejahteraan dan ukurannya", (online), (http://ahmadheryawan.blogspot.co.id /kesejahteraan-dan-ukuran, Diakses pada 9 Maret 2015)

Masyhuri. 2005. Teori ekonomi dalam Islam. Yogyakarta : kreasi wacana.

Midgley, James, Martin B. Tracey dan Michelle Livermore (ed). The handbook of social policy. London.

Miles. 1985. Social Indicator for Human Development. From Printer Publicers.

Miyagi, Khea. 2014. Perbandingan Kesejahteraan Antara Pengusaha dan Pegawai Perspektif Maqashid Syariah di Kelurahan Kejawan Putih Tambak Surabaya. Skripsi tidak diterbitkan. Surabaya, Fakultas Ekonomi dan Bisnis Universitas Airlangga.

Moleong, Lexy J. 2014. Metodologi penelitan kualitatif. Edisi revisi. Bandung : Remaja Rosdakarya.

Mufraini, M. Arief. 2006. Akuntansi dan Manajemen Zakat. Edisi pertama. Jakarta : Prenada Media Group.

Nazir, Mohammad. 1988. Metode Penelitian. Jakarta : Ghalia Indonesia.

Otoritas Jasa Keuangan. 2014. Statistik Perbankan Syariah 2014.

Pusat Pengkajian dan Pengembangan Ekonomi Islam. 2008. Ekonomi Islam. Jakarta: PT. Raja Grafindo Persada.
Pramandhika, Ananto. 2011 . Motivasi Kerja Guru TPQ di Kecamatan Semarang Selatan. Jurnal Pendidikan Undip, 15 Juni 2011 . Semarang, Volume 2 hal : 23.

Qardhawi, Yusuf. 2007. Halal dan haram. Bandung : Penerbit Jabal.

Timorita, Yulianti. 2009. "Perbankan Islam di Indonesia (Studi Peraturan Perundangundangan)". Jurnal Penelitian IImu-ilmu Sosial FENOMENA, Volume 01 Nomor 2 (Online), (http://journal.uii.ac.id, diakses 12 Maret 2015).

Ryandono, Muhammad Nafik Hadi. 2008. Ekonomi ZISWAQ (Zakat, Infaq, Shadaqah dan Waqaf). Surabaya: IFDI dan Cenforis.

-------. 2009. Bursa Efek dan Investasi Syariah Kajian Pelanggaran PrinsipPrinsip Syariah Pada Transaksi Bursa Efek Konvensional. Surabaya: Amanah Pustaka.

-------. 2010. Peran dan Pengaruh Penghimpunan Dana Terhadap Penyaluran Dana dan Faktor Kinerja Bank Serta Kesejahteraan Karyawan Bank Islam di Indonesia. Disertasi tidak diterbitkan. Surabaya : Pascasarjana UNAIR Surabaya.

Shihab, M. Quraish. 2009. Tafsir Al-Mishbah: pesan, kesan, dan keserasian AlQur'an. Vol. 1. Edisi baru. Cetakan pertama. Jakarta: lentera hati.

Sugiyono. 2009. Metode Penelitian Kuantitatif, Kualitatif dan R\&D. Bandung: Alfabeta. 
Sardar, et al/Jurnal Ekonomi Syariah Teori dan Terapan Vol. 3 No. 5 Mei 2016: 391-401; KESEJAHTERAAN DALAM PERSPEKTIF ISLAM PADA KARYAWAN BANK SYARIAH

Sutrisno, Edy. 2009. Manajemen Sumber Daya Manusia. Edisi Pertama. Cetakan Pertama. Jakarta: Kencana

Syarifuddin, Amir. 2008. Ushul figh jilid dua. Edisi pertama. Cetakan keempat. Jakarta: kencana.

Tasmara, Toto. 2002. Membudayakan Etos Kerja Islam. Jakarta: Gema Insani.

Terjemahan Hadits Shahih Bukhari I-IV. 1992. Jakarta : PT. Bumirestu

Wibowo. 2013. Manajemen Kinerja. Edisi Ketiga. Cetakan Keenam. Jakarta: Rajawali Pers

Widjaja, A. W. 2006. Administrasi Kepegawaian. Jakarta. Rajawali World bank. 2011. Defining Welfare Measures, (http://web.worldbank.org, diakses 12 Maret 2015)

Zadjuli, Suroso Imam. 2008. Prinsip-prinsip Ekonomi Islam. Surabaya: FE Unair. 